\title{
Gramática dos meios no contexto das linguagens icônicas
}

\author{
Grammar of the means in the iconic language context
}

\begin{abstract}
Irene de Araújo Machado I irenemac@uol.com.br
Bolsista Produtividade PQ-2. Livre Docente em Ciências da Comunicação pela Escola de Comunicações e Artes da Universidade de São Paulo em 2011. Bacharel em Letras, pela Faculdade de Filosofia Letras e Ciências Humanas da USP (1977); Doutora em Letras pelo Departamento de Teoria Literária e Literatura Comparada da USP (1993) e Mestre em Comunicação e Semiótica pela Pontifícia Universidade Católica de São Paulo (1985). Atualmente é Professora Associada da Escola de Comunicações e Artes da Universidade de São Paulo onde ministra a disciplina Semiótica da Comunicação na Cultura e orienta pesquisas de mestrado e doutorado. Como Pesquisadora do

CNPq (PQII) desenvolve a pesquisa: "Performances dos diagramas argumentativos em textos comunicacionais" (2010-2013), sendo líder do Grupo de Pesquisa Semiótica da Comunicação. Coordenou o Projeto "Semiosfera: Espaços Semióticos Compartilhados" www.usp.br/semiosphera ( Edital Universal do CNPq, 2005). Edita a revista semeiosis.com.br..
\end{abstract}

Resumo: Como se organizam os meios para que seus produtos sejam oferecidos a seus usuários como produtos de comunicação? Esta é a pergunta que sustenta e justifica o estudo da gramática dos meios, segundo a articulação de códigos eletrônicos geradores das linguagens icônicas em processos perceptuais e cognitivos. Orienta-se pelas exploraçóes que Marshall McLuhan formulou em suas análises e exercícios de seu projeto pedagógico e também na metodologia semiótica dos processos de articulação sintática, semântica e pragmática. Palavras chave: Gramática dos meios. Linguagem icônica. Percepçáo

\begin{abstract}
How do media organize themselves so that their products are offered to its users as forms of communication? This is the question that sustains and justifies the grammatical study of media according to the articulation of electronic codes and the iconic languages of perceptual and cognitive process. Following Marshall McLuhan analysis and pedagogic exercises the essay is oriented by the semiotic process based on syntactic, semantic, and pragmatic methodology
\end{abstract}

Keywords: Grammar of media, Iconic languages. Perception 


\section{Introdução}

O exercício didático que inclui análises de produtos culturais transmitidos pelos meios de comunicação impressos ou audiovisuais, com ampla circulação social, não era prática do cotidiano escolar nos anos de 1950, quando Marshall McLuhan inicia suas atividades de educador. Não obstante, o teórico canadense insistiu em sua hipótese de que os meios não só ofereciam conteúdos desafiadores em suas elaboraçóes culturais, como também ameaçavam o prestígio da formação escolar e do pensamento teórico consagrados pelos parâmetros da cultura letrada.

Com o objetivo de enfrentar o desafio e refletir sobre a ameaça, McLuhan transforma a sala de aula, em particular, e os espaços de informação, em geral, incluindo cidades, em espaços de discussão e produção de pensamento. Com o exame de páginas de jornal e revistas; programas de rádio e de televisão; filmes e anúncios publicitários; charges e fotos; de painéis dispostos em espaços públicos de grandes centros urbanos exercita o pensamento crítico com finalidades teóricas. Em seu gesto, elevou os meios, os produtos e os processos da comunicação tecnológica à condição de objetos renovadores dos conteúdos didáticos, da redefinição do espaço escolar e, sobretudo, do redirecionamento da investigação acadêmica comprometida com as questóes de seu tempo. Em última análise, os meios se tornaram fonte fundamental da teoria da comunicação.

Se a resistência aos meios de comunicação foi, num passado não tão remoto, declarada, o movimento de incorporação não foi nada sorrateiro, a despeito da presença dos meios na vida social. Para isso, sem dúvida, contribuiu o imenso trabalho de todos aqueles que acenaram favoravelmente à ideia de que os produtos dos meios tecnológicos de transmissão de informação não apenas promoveram novas formas de comunicação e de interação social, como também se tornaram responsáveis pelo desenvolvimento de novas linguagens culturais e de "consciência sensorial" (SONTAG, 1987, p. 346). O projeto educativo de McLuhan, desenvolvido nos exercícios de análise e de treino de percepção com vistas à sistematização cognitiva, ocupa um lugar significativo nessa história, ainda que nem sempre seja lembrado como merece.

Desde os exercícios iniciais, McLuhan entendeu a necessidade de observar os dispositivos de construção da informação elaborados em termos de códigos culturais. Atribuiu a mecanismos de tradução da informação, a transformação dos processos elétrico-eletrônico em informação codificada, aprimorando aquilo que fora iniciado pelos processos mecânicos de registro da luz, como a fotografia. A partir daí, vê reforçada a hipótese dos códigos da informação elétrica como modelo operacional de dispositivos técnicos como prensa, câmeras, cabos ou redes elétricas. Para além do alfabeto, mosaicos da tipografia impressa, ondas sonoras radiofônicas, recortes fotográficos da luz, sequências das tomadas fílmicas, em planos ou feixes 
luminosos dos tubos de televisão, e, até mesmo, padróes de ondas emitidas por satélites, todos se mostravam dotados de capacidades para gerar formas culturais de representação do mundo como códigos e linguagens.

McLuhan não hesitou em atribuir à eletricidade o papel de força motriz potencial das novas estruturas significantes da cultura de meios. Derivou daí a noção de linguagem icônica e, a partir dela, se voltou para a análise dos produtos tipográficos, fotográficos, cinematográficos, televisuais e infográficos em circulaçáo nos meios, extrapolando os limites dos livros. Pelo viés da transformação e da tradução dos códigos elétricos em linguagens icônicas, entendeu a mudança nas formas de percepção e de cognição, moduladas, assim, pelo engenho de códigos não diretamente alfabéticos.

O projeto de McLuhan avançou na hipótese de que os meios desenvolvem códigos e linguagens icônicas que, organizados, moldam os processos perceptuais e cognitivos. A trama de tais organizaçóes, contudo, desafia o legado da cultura letrada alfabética. Os meios e seus processos de construção sensorial e cognitiva demandam uma gramática dos meios baseada nas estruturas e padróes dos processos elétricos.

Tornada síntese de seu projeto educativo, a gramática dos meios propóe um método comparativo de leitura e de análise que, partindo do treino da percepção no ambiente sensorial gerado pelos meios, encaminha-se para a estruturação dos códigos das linguagens icônicas traduzidas sob forma de padrōes de composição: mosaicos gráficos em superfícies; montagem de planos de luz em películas; telas e espaços ressonantes. As linguagens icônicas pareciam configurar relaçôes de tradução de códigos (ondas, partículas, luz, circuitos) por meio de padróes e organizados em páginas, telas, superfícies e espaços ambientais.

O objetivo primordial deste ensaio é tratar das linhas de força deste pensamento teórico nascido de um projeto de educação dos sentidos pelos meios. Espera-se compreender o papel da gramática dos meios a partir das linguagens transformadas pelos códigos culturais em processo de expansão dos padróes da tecnologia mecânica e eletro-eletrônica, fora, porém de qualquer determinismo tecnológico. Com isso, espera-se dimensionar a contribuição de McLuhan para o debate acadêmico que se ampliou, a partir dos anos de 1960, para consolidar a análise crítica dos meios, em seus vieses especulativo e teórico.

\section{Treino da percepçáo no entendimento da informaçáo elétrica}

Devemos à eletricidade o desenvolvimento da noção de padrão como processo de composição de códigos nas linguagens icônicas exploradas pelos meios no trato da informação. Logo, é a noção de padrão que pode nos conduzir na compreensão da gramática dos meios fora do sistema alfabético. Contra a noção de totalidade gerada por unidades, McLuhan segue noçóes de efeitos, de mosaico e 
de circuito: todos baseados em funcionamentos através de padróes estruturais cujas articulações são dimensionadas na percepção. Com isso, a propriedade do padrão revela ser o envolvimento capaz de traduzir estruturas em esferas sensoriais.

Considerando-se que a eletricidade introduz o padrão como processo de organização da informação, a gramática dos meios se inicia pelo reconhecimento da informação elétrica como padrão baseado nos circuitos de um campo unificado (McLUHAN, 1977, p. 57) a movimentar processos sensoriais. Para isso, há que se apurar o treino da percepçáo sem o qual o processo não chega a constituir-se em efeito sensorial. Sem treino da percepçáo nenhuma observação ou ação cognitiva seriam possíveis.

Treino de percepção fora a forte herança da formação escolar de McLuhan e também de seu doutoramento em Cambridge. Não é de se estranhar que tenha sido o exercício dominante na atividade acadêmico-didática orientada pelo trabalho analítico dos meios em campos sensoriais. O treino da percepção sugeria a McLuhan não apenas a única rota para sair da ignorância, como também o caminho certo para atingir o entendimento do que estava acontecendo na cultura sob o reinado de meios. Este fora o legado de Harold Innis no estudo da cultura que, pelo "viés da comunicação», alertava para a importância da percepção de angulaçôes e contrastes em diferentes esferas, de meios e ambientes.

Da percepção distintiva de padróes depende, igualmente, a elaboração do pensamento que confere o estatuto de linguagem às realizaçóes dos signos contínuos da eletricidade. Quer dizer, ao se manifestar como um sistema operacional de informação, o circuito elétrico projeta-se como forma de representação e fonte de produção de códigos geradores de linguagem. Quando McLuhan definiu a eletricidade como "informação pura" (McLUHAN, 1971, p. 71), abriu caminho para o entendimento da tecnologia de produção de uma forma de linguagem que, por não se apoiar diretamente no código alfabético, elaborava-se em torno de estruturas e padróes icônicos. Esta se tornou a marca fundamental do pensamento semiótico que atribuiu ao treino da percepção a condição distintiva das novas formas e ambientes culturais.

Em linhas gerais, o raciocínio que permite entender como linguagem as estruturas de significação elaboradas sem o concurso dos signos verbais (ou linguísticos) resulta de inferências fundadas no método comparativo. Isto é, quanto maior a clareza da distinção entre língua e linguagem no plano da própria história das formaçóes culturais, menor o risco de simplesmente impor aos meios a gramática da língua, com a consequente perda irremediável da semiose dos códigos elaborados nas articulaçôes de natureza elétrica.

Conforme estudos de McLuhan, após o advento da prensa de Gutenberg, os esteios da cultura alfabética foram edificados pela distinção e fortalecimento das línguas nacionais, consagrados pelo livro e cultivados nas salas de aulas da escola, nos salóes literários e nas mais variadas transformaçóes da escrita alfabética. Tudo isso é um legado histórico insuspeito. Salvaguardá-lo, porém, está 
longe de ignorar as transformaçóes posteriores que os meios técnicos, dos circuitos elétricos e também da câmera fotográfica produziram, contribuindo para a geração de linguagens que não são línguas. Este é o dilema das linguagens da comunicação geradas pelos meios e processos das tecnologias não diretamente alfabéticas. Quando atribui aos códigos da informação elétrica o caráter gerador das linguagens icônicas, McLuhan não descarta o poder das línguas nacionais nem o campo de forças das instituiçóes linguísticas.

Contudo, é evidente que seu entendimento dos padróes estruturais do processamento de dados nos contextos da informação em circuitos elétricos o salva das transposições reducionistas. Todos os exercícios conduzidos no sentido de aprimorar o treino de percepção se abrem para a consciência da linguagem dos meios na radicalidade de seus códigos e padrôes estruturais enquanto informação elétrica.

Nada disso autoriza a especulação equivocada de superioridade de uma formaçáo cultural em relação a outra que só reforça a velha ordem ética de separaçáo da cultura em polos (alta e baixa cultura; erudito e massivo e outras dicotomias estéreis). Em vez disso, há o reconhecimento da dialética emergente nos espaços ocupados pelas línguas, pelo livro e pela escola, na colaboração para o surgimento de códigos, suportes e ambientes de outra natureza.

Apesar da declarada disputa, nem sempre há eliminação, daí a necessidade de um acurado processo de percepçáo para distinguir os signos em luta na constituição dos sistemas de escrita, de suportes e do próprio espaço de aprendizagem. Em vez de alfabeto, nas páginas, nas superfícies eletrônicas de telas audiovisuais - a jogar com ondas sonoras, pontos de luz, formas gráficas, projeçôes audiovisuais e cinéticas - o que vemos são estruturas e padróes gerados pela informação elétrica. Por isso, os exercícios de leitura e análise que ignoram os códigos e signos do contexto elétrico negam a própria cultura que os sustenta.

A gramática dos meios foi pensada para não correr os riscos de hierarquização da cultura e de submissáo das formas culturais de modo a consagrar um conjunto em detrimento de outros. Por isso, insistiu no treino da percepção de signos nascidos da semiose não restrita ao alfabeto e à palavra. Ao que McLuhan infere: "sem uma compreensão da gramática dos meios de comunicação, é impossível ter esperança de se atingir uma consciência contemporânea do mundo em que vivemos" (McLUHAN, 1971, p. 16). Como todo humanista, sabia ser a gramática, associada à lógica (ou dialética) e à retórica, a articulação do Trivium - o grande campo de estudo para a disciplina da mente.

O projeto pedagógico de McLuhan se orienta pelo entendimento dos meios que, a partir de padrôes e estruturas da informação elétrica, desenvolvem códigos e linguagens traduzidas em formas sensoriais. Se viver num ambiente de informação significa manter-se exposto à ação dos meios e com eles interagir sensorialmente, então, tudo neste ambiente significa. Todavia, em torno daquilo que aparece como mero entretenimento dos sentidos, processos de percepção e de cognição são desenvolvidos e estão a demandar aprendizado, de modo a serem traduzidos 
em conhecimento histórico e social. Esta é a hipótese que encaminha o treino da percepção para o exercício de distinção de signos na atividade sensorial e cognitiva.

\section{Exposição continuada aos meios: percepção, entretenimento, cognição}

Comparada com a tecnologia do alfabeto, a informação elétrica distingue-se por se apresentar como "informação pura" envolvente, que submete o sensório a experiências de exposição continuada. Se, por um lado, promove um mergulho no ambiente de informação, por outro, a exposição continuada a estímulos sensoriais desencadeia uma espécie de sentimento de alienação. Delineia-se um conflito entre participação e alienação que McLuhan concebe como «entretenimento». Afastemo-nos por um momento da noção de entretenimento como desígnio dos produtos da cultura de massa de baixo ou nenhum valor intelectual. Tratemos da disposição sensorial de percepção ambiental, tornada uma das noçóes mais desconcertantes do universo conceitual de McLuhan, sobretudo quando equaciona comunicação e educação.

Entretenimento como ato de compenetração pressuposto no exercício cognitivo. As ideias sobre o entretenimento como modelo sensorial cogitado em contextos de grande envolvimento e participação foram introduzidas no livro The Mechanical Bride (1951). Nele se exploravam os modos como os meios funcionam no ambiente, como geram extensóes dos sentidos corpóreos e os ampliam em interaçôes.

A noção de entretenimento foi conceptualizada na análise do conto do escritor americano Edgar Allan Poe, A Descent into the Maelström (McLUHAN, 2002, p. V). Definido como forma de distração da mente num passatempo, McLuhan flagra no ato de se entreter uma elevação do espírito no auge de um envolvimento. Quanto mais intensa a concentração, maior a alienaçáo e, paradoxalmente, maior a possibilidade de uma reversão, de um salto de esclarecimento.

No conto, o alheamento desencadeia um processo de auto-aprendizagem na narrativa de um dos personagens, um pescador, sobre a terrível experiência que vivera num dia em que uma imprevisível tempestade despertou a fúria do redemoinho Ström, na costa da Noruega, engolindo todos os barcos e navios que navegavam pela regiáo. Em meio ao pânico e à necessidade de lutar para sobreviver, o pescador conseguiu substituir o desespero pelo exame cuidadoso do fenômeno que estava prestes a transportá-lo do tempo para a eternidade. Neste cenário de entretenimento, a mente do personagem ficou de tal modo invadida por conjecturas (guesses), que ele se sentiu dominado por um delírio assombroso. Quanto mais próximo o torvelinho, mais sua mente operava cálculos de possibilidades para um deslocamento libertador que tanto seria para o tempo quanto para a eternidade. Quanto mais olhava o movimento das águas, mais se compenetrava do movimento que nela se operava. Num instante epifânico, ocorreu-lhe uma repreensão do espírito: como, num momento como esse, ele poderia encontrar distração para seu pensamento, tentando imaginar 
qual seria a sequência de descida dos escombros, dos barcos, das pessoas, para o interior do torvelinho? $\mathrm{O}$ fato é que, na análise detalhada da ação da água no turbilhão, descobriu um modo de se proteger, resistir e sobreviver ao furor do redemoinho. Deixou de ver o furor das águas para sintonizar os padróes de sua conduta, derivando daí modelos de ação.

Se o reconhecimento de padróes em meio às forças tumultuosas e esmagadoras do Maelström induziu o pescador à salvação, o entretenimento assim revelado teria muito a dizer dos comportamentos em ambientes dos meios eletrônicos. Os meios de comunicação, em sua vertiginosa movimentaçáo de circuitos elétricos, compunham um ambiente muito semelhante ao quadro de voracidade do redemoinho ström. Neste ambiente, o comportamento também é estimulado sensorialmente: na combinação de envolvimento e alheamento. Trata-se de uma reação física e mental, de corpo e espírito conjugados, capaz de traduzir-se em princípio heurístico da percepção de padrōes (McLUHAN, 2005, p. 249-52).

Comparativamente, há pelo menos dois vieses a serem considerados. Do ponto de vista especulativo, o entretenimento traduz um regime de pensamento muito próximo dos estudos capazes de fomentar probabilidades e descobertas de meras possibilidades. Do ponto de vista sensorial, o entretenimento configura a "meditação pelo tato", uma atividade que nasce de efeitos produzidos em ambientes e neles se propagam, tomando conta do corpo (McLUHAN, 1977, p. 32). Se, por um lado, a tatilidade se manifesta como elaboraçáo do contato corporal desordenado que, pelos sentidos, atinge a mente, por outro, evidencia a percepção de um padrão. Em ambos os casos o entretenimento distancia-se da noção de passatempo como diversão sem nenhuma interferência no corpo e na mente. É de linguagem do entretenimento que estamos falando e não daquilo que veículos de comunicação, em nome de interesses e benefícios exclusivos, transformaram em produtos de consumo inconsequente.

Exposição continuada aos meios significa, sobretudo, estímulo da consciência sensorial, passagem de um estado de coisas para outro, com ampliação do espectro de apreensão daquilo que chega simultaneamente pelos olhos, ouvidos e tato. Para isso, propóe o exercício:

se o estudante da teoria da informação apenas meditar no poder da luz elétrica em transformar toda e qualquer estrutura de espaço-tempo, de trabalho ou da sociedade na qual penetra ou com a qual entra em contato, certamente disporá da chave da forma de energia que preside a todos os meios e que molda tudo o que toca. $\grave{A}$ exceção da luz, todos os meios andam aos pares, um atuando com conteúdo do outro, de modo a obscurecer a atuação de ambos (McLUHAN, 1971, p. 71).

Sem dúvida, o conceito de «entretenimento» não pode ser descartado dessa inspeção. Basta seguir os passos de suas análises dos meios audiovisuais e cinéticos como a televisão, o cinema, o rádio, e em todos os meios que transformaram a tela num ambiente potencial dos vórtices da energia elétrica. Neles, os conceitos de linguagem icônica, de espaço acústico e de espectador-tela extrapolam todos os limites da ousadia. 


\section{Relevos da linguagem icônica}

Graças ao treino da percepção, o método comparativo adquire a função de distinguir a sintaxe das diferentes tecnologias em seus códigos e a semântica das estruturas de significação traduzidas nas extensôes de um meio em relação ao outro. Se o código alfabético aprimorou a percepção de unidades em signos discretos como a palavra e o mundo verbal de seu entorno escrito e letrado, o código elétrico dos meios ativou a percepção para campos sensoriais de signos contínuos funcionando a partir de padróes tais como as configuraçôes audiovisuais da informação luminosa. Contudo, não se trata de opor signos discretos a contínuos, mas de entender o processamento de suas combinaçóes em arranjos e padróes de funcionamento quando um código interfere no outro e gera transformaçóes de outra natureza. Tal foi o comportamento que se observa quando se percebe que a natureza discreta do código alfabético não está imune a traduçóes. McLuhan observou em páginas impressas de jornais, anúncios e marcas de tradução de palavras em signos contínuos, igualmente modificados em padróes estruturais dos circuitos elétricos dos meios eletrônicos, seja do cinema, da televisão oudas luzes de gás neon nos centros urbanos. Nesse sentido, as linguagens icônicas se manifestam como estruturas codificadas no movimento de suas extensões.

McLuhan propóe a noção de mosaico para sintetizar a sintaxe relacional que sustenta um conhecimento do mundo baseado em padróes e náo em unidades. Enfatiza a combinação de estruturas de significação e também de intercambialidade de funçôes, tais como aquelas que foram alvo da análise da página de jornal que abre o seu livro The Mechanical Bride. Nela o mosaico resulta da combinação entre a dimensão gráfico-visual da palavra com os diagramas da composição multidirecional de um espaço que convida, não para a leitura da página «deitada», mas da página «erguida» num espaço público ou na banca de jornal. Se, por um lado, o grafismo, visualidade, espacialidade surgem como padróes estruturais da página, por outro, os efeitos produzidos na interação em ambientes valorizam os processos relacionais. Com isso, a noção de mosaico articula-se no arranjo dos elementos de sua constituição interna com os efeitos externos ambientais.

Das análises das histórias em quadrinhos, da fotografia, do cinema e da televisão, dos anúncios em espaços públicos, McLuhan examina alguns padróes de composição das linguagens icônicas pelos códigos da luz. Traços, ângulos, planos, pontos, tomadas, recortes, sequências, composição figura/fundo, montagem, edição - eis alguns dos padrões que definem a composição daquilo que emerge nas superfícies de telas, cujas proporçóes e dimensionalidades distinguem as significaçôes. As linguagens icônicas evocam, pois, representaçôes que jogam com relaçóes de dentro e fora; figura e fundo; luz e sombra; encontrando nas telas o local privilegiado de sua constituição semiótica.

Nesse sentido, tudo o que McLuhan observara a respeito das linguagens icônicas projetadas pela luz nas telas de televisão apenas completaram as 
exploraçóes iniciadas nas análises dos mosaicos de luz, nos diagramas nas páginas de jornal, nas inscriçóes de superfícies rupestres e, até mesmo, nas iluminuras. Em todas essas produçóes culturais, as linguagens icônicas compóem, mais do que imagens visuais, ambientes de luz que oscilam entre as relaçóes de similaridade (de figuras) e as de contiguidade (de fundo). O treino de percepção aqui demanda muito mais a capacidade de despertar analogias do que de seguir o modo analítico, tão comum nas operaçôes da linguagem verbal. No caso das linguagens icônicas elaboradas pelos códigos elétricos, o mosaico encaminha as investigaçóes em que as superfícies e suportes são telas diagramaticamente construídas por padróes de circuitos elétricos. Aquilo que se convencionou chamar de imagens audiovisuais nada mais seria senão arranjos de padróes produzidos por feixes de luz, estruturas contínuas geradoras de linguagens icônicas de contatos elétricos e ambientais. Não se trata de uma continência na superfície mas de padrôes que alcançam os ambientes através de telas que só podem ser limitadas à audiovisualidade se, neste conceito, estiver dimensionado o relevo ambiental do contato, tal como os mosaicos de luz das catedrais góticas, entendidos por McLuhan como puro efeito ambiental percebido pela «luz através».

\section{Plasticidade dos códigos de luz: entre a projeção e a ressonância}

Quando McLuhan afirmou que a tela de televisão, apesar de reproduzir processo audiovisual e cinético, não se limitaria a representar um espaço da mesma natureza, visto que o padrão de funcionamento dos feixes de luz constitui a dimensão tátil de suas emissóes, ele atribui aos códigos elétricos a capacidade de expandir-se sob forma de outros espaços. Espaço deixa de ser continente para as coisas para acolher a reverberação que não se manifesta visualmente, mas tem poder de envolvimento, de simultaneidade. A tela de televisão apresentava, assim, a possibilidade de construção de um espaço de fronteira entre visualidade e invisibilidade, em que a luz potencializa um padrão não tão evidente de sua constituição: a ressonância.

Contrariamente ao que se poderia supor, a condição acústica do espaço náo se vincula nem ao som e muito menos pode ser situada como contracampo da visualidade. Acústico é, sobretudo, padrão de percepção do espaço em termos de vibração e reverberação, daí a ressonância. Trata-se de uma condição intuitiva como toda percepção que busca os indícios da constituição dos ambientes, como aqueles gerados pela informaçáo luminosa, muito propriamente denominada «luz-ambiente». Comparativamente, os meios de tela evocam o espaço acústico naquilo que se percebecomo «meio-ambiente». Não vamos repetir aqui especulaçôes já exploradas anteriormente (Autor), mas reforçar a plasticidade do efeito icônico da luz e, consequentemente, o desdobramento na construção do espaço acústico (CARPENTER; McLUHAN, 1980) como ressonância e reverberação.

Por efeito icônico entende-se a plasticidade da imagem eletrônica em movimento para o ambiente externo ao contexto de sua produção. Aquilo que já foi entendido como busca de complementaridade explora outra 
característica: a participação tátil ativa. Busca-se a integração de circuitos, do olho ao ouvido, do espaço interno para o espaço externo. As imagens eletrônicas de tela, sobretudo aquelas geradas no backscreen se tornaram o experimento por excelência de tudo que foi concebido como plasticidade dos códigos de luz na composição da trama tátil, ambiental, ressonante.

Imerso na luz da tela, ao mesmo tempo em que lê suas estruturas visuais e sonoras, o observador percebe, para além da visualidade, ressonâncias de som e de tato: os feixes e trama de luz e som esparramam-se pelo espaço e corpos. Eis que as tramas se confundem: "quem»é a tela? A trama elétrica ou a trama do espaço acústico conjugada com o participante no ambiente? A superfície ou o ambiente percebido? (McLUHAN, 1971, p. 351). McLuhan náo hesita: o homem-tela no espaço acústico ressonante, tal como representado no conceito gráfico que se segue.

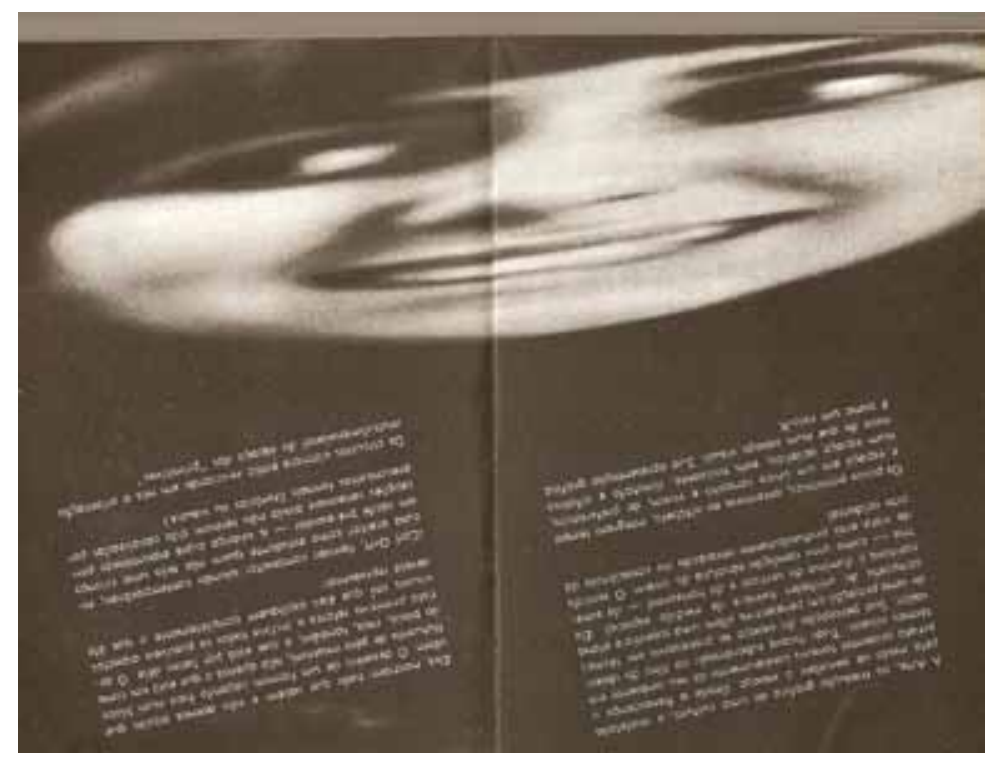

Os meios são as massa-gens (McLuhan \& Fiore, 1969: 82-3).

A foto integra o livro gráfico de McLuhan em parceria com o designer Quentin Fiore. Nela se constrói a imagem do espectador-tela e seu campo visual em movimento ressonante. Difícil dizer a qual espaço visual a imagem se refere. Na dúvida, as páginas reproduzem um texto invertido em relação à figura; o grafismo exige sua participaçáo no reposicionamento do campo gráfico-visual de modo a propiciar a leitura do texto verbal. Se, a leitura do livro, convida o leitor a se reposicionar no espaço visual, tal apelo não é fortuito: trata-se de oferecer uma possibilidade de contato com a ambivalência que este meio de comunicação elabora no nível estrutural de sua constituição enquanto meio elétrico audiovisual e cinético.

A experiência de atravessamento de uma dimensão interna para a externa, ou a inversão dos campos de leitura, toca também na noção de McLuhan de televisão como envolvimento que demanda participação em profundidade. Para alcançá-lo, é preciso atravessar os limites da audiovisualidade e alcançar a condição tátil da luz que ressoa no espaço para tocar nos corpos. 
Aquilo que se afirmou a respeito dos códigos eletrônicos, do processo icônico da luz, moldando tanto a audiovisualidade cinética quanto o espectador-tela num espaço ressonante, explicita as articulaçôes fundamentais da gramática do meio televisão, sobretudo, a qualidade de meio-ambiente formado na percepção de padróes de funcionamento.

De posse do conhecimento gramatical, o que se colocaria a seguir? Segundo a gramática dos meios, o espaço acústico, construído pelas mídias de tela, depende da ação complementar perceptiva, de onde emerge o envolvimento, sugerido aqui na plasticidade dos seres nos quais a luz se projeta para o espaço de convivência, a ponto de ser confundida com eles. Ora, não seria esta plasticidade um evento produzido pelo envolvimento de distração da mente, tal como aquele que McLuhan flagra no conto de Edgard Poe? Não é deste envolvimento que tratam os estudiosos de programas como telenovelas e seriados em suas investigaçôes? Não é este o entretenimento que os próprios noticiários televisuais perseguem quando jogam com as atrocidades das grandes tragédias potencializando as ampliações tanto no espaço público quanto no espaço de intimidade? Também não é a plasticidade icônica da ressonância que emergiu como a grande novidade da exploraçáo da música produzida em regime televisual? Não há resposta às questóes que buscamos nesse momento, mas a consciência sensorial do viver no espaço acústico ressonante em que o uso dos meios marca a distinção do viver no espaço visual criado pela cultura alfabética. A plasticidade evocada na consciência sensorial do espaço ressonante não seria possível sem a percepção de padróes de conduta e de funcionamento.

\section{Conclusão: 0 papel da gramática dos meios na ação educativa}

Buscamos em nossa análise, um percurso possível da gramática dos meios em sua (1) articulação sintática estrutural de códigos e linguagens, (2) no envolvimento semântico provocado pela percepção e formas sensoriais e (3) na construção pragmática do espaço ressonante intuitivo centrado nos usos e usuários dos meios como bens culturais. Com base neste percurso, entendemos a proposta de gramática dos meios centrada no papel dos códigos elétricos, das linguagens icônicas e no espaço ressonante de relaçóes ambientais.

Situamos no ponto de partida de nosso percurso a importância do treino da percepção para a emergência da consciência sensorial, sem a qual a interaçáo com os meios não alcançaria a plasticidade de suas ocorrências. É chegada a hora de completar este raciocínio: tudo o que foi apresentado evidencia a necessidade de estudo e aprendizagem. A gramática dos meios nasce como um programa de educação em ambientes sensoriais voltados para o desenvolvimento cognitivo.

Nesse ponto, os exercícios de McLuhan potencializaram aquilo que, por exemplo, a educadora italiana Maria Montessori formulara em sua prática pioneira de construção de currículo escolar como ambiente pedagógico. Ao desenhar números, letras e mapas com relevos táteis; planejar mobiliário 
em espaços de circulação de corpos, de modo que o ambiente fosse favorável ao desenvolvimento sensorial e cognitivo, o trabalho escolar dava um grande passo na promoçáo da educação pelos meios como forma de descoberta e de autonomia (McLUHAN, 2005, p. 85). Até onde é lícito supor, Montessori derrubou, senão os muros, pelo menos as paredes da escola para que as crianças desfrutassem do ambiente social através da consciência sensorial.

Cava-se um fosso entre instrução e educação. Enquanto a instrução se restringe à absorção de dados, a educação aceita o desafio de trabalhar os dados porque não ignora que os dados estão na base do desenvolvimento de padróes. McLuhan acredita que aprender a lidar com dados é tarefa essencial para quem vive na sociedade de meios e de informação. Nesse sentido, os dados, não são um a priori, mas organizaçóes de padrôes disponíveis para o trabalho em diferentes lugares do espaço social. Além disso, o trabalho com dados exige muito mais a ação do raciocínio indutivo do que da dedução, na demonstração de formulações a priori estabelecidas. Indução exige muito mais da percepção no ambiente.

Se é verdade que os meios de comunicação ampliaram a possibilidade de elaboração de linguagem, seja pelo trabalho com padróes na tipografia, fotografia, cinematografia, videografia e infografia em meios digitais, não pode ser menos verdadeira a afirmação que prega a necessidade de ampliação do processo iniciado com a alfabetização. Há, contudo, que atentar para uma distinção importante: sendo a assimilação para o desenvolvimento da escrita e da leitura a principal demanda do alfabeto, caberia aos meios de comunicação (mecânicos, elétricos, informáticos) o aprimoramento do processo de modelização de linguagens (Autor), pré-requisito sem o qual a educação em meios não acontece. Aquilo que precariamente chamamos de alfabetização semiótica corresponderia ao trabalho de descoberta das possibilidades educativas no ambiente de meios.

Acrescentamos, por nossa conta e risco, a modelização de linguagens à base do estudo gramatical dos meios. A educação pode não ter se iniciado com a invenção do alfabeto, contudo, deve a ele seu desenvolvimento e, sobretudo, a descoberta de que seu princípio elementar repousa sobre a mediação de processos interativos impulsionados por uma força e direcionados para um fim: a descoberta. As forças, como se sabe, são variáveis da energia e não se mantêm, pois, inalteradas em seu movimento rumo a suas finalidades. $\mathrm{O}$ mesmo se pode dizer do alfabeto como meio interativo que impulsionou o desenvolvimento dos processos de modelização aos quais compete à educação desvendar. Os meios de comunicação, como todo sistema cultural, operam com necessidades, dentre elas, de ampliação das possibilidades e caminhos para a descoberta. É possível que a educação decline desta que sempre foi sua tarefa? 


\section{Referências Bibliográficas}

CARPENTER, E. \& McLUHAN, M. Espaço acústico. In Revolução na comunicação (trad. Álvaro Cabral). Rio de Janeiro: Zahar, 1980.

McLUHAN, M. A galáxia de Gutenberg. A formação do homem tipográfico (trad. Leônidas G. de Carvalho e Anísio Teixeira). São Paulo: Cia. Editora Nacional, 1977.

McLuhan por McLuhan. Conferências e entrevistas (S. McLuhan and D. Staines, orgs.) (trad. A.P. Danesi). Rio de Janeiro: Ediouro, 2005.

Os meios de comunicação como extensóes do homem (trad. Décio Pignatari). São Paulo: Cultrix, 1971.

McLUHAN, M. \& FIORE, Q. Os meios são as massagens (trad. Ivo Pedro de Martins). Rio de Janeiro:Record, 1969.

McLUHAN, M. \& PARKER, H. O espaço na poesia e na pintura através do ponto de fuga (trad. Edson Bini e outros). São Paulo: Hemus, 1975.

SONTAG, S. Contra a interpretação (trad. A.M. Capovilla). Porto Alegre: L\&PM, 1987. 